Año LXXXI. urtea $276-2020$ Enero-abril Urtarrila-apirila

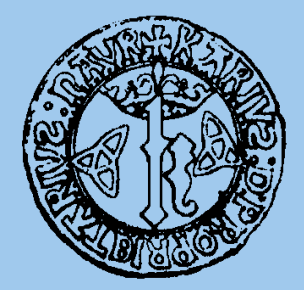

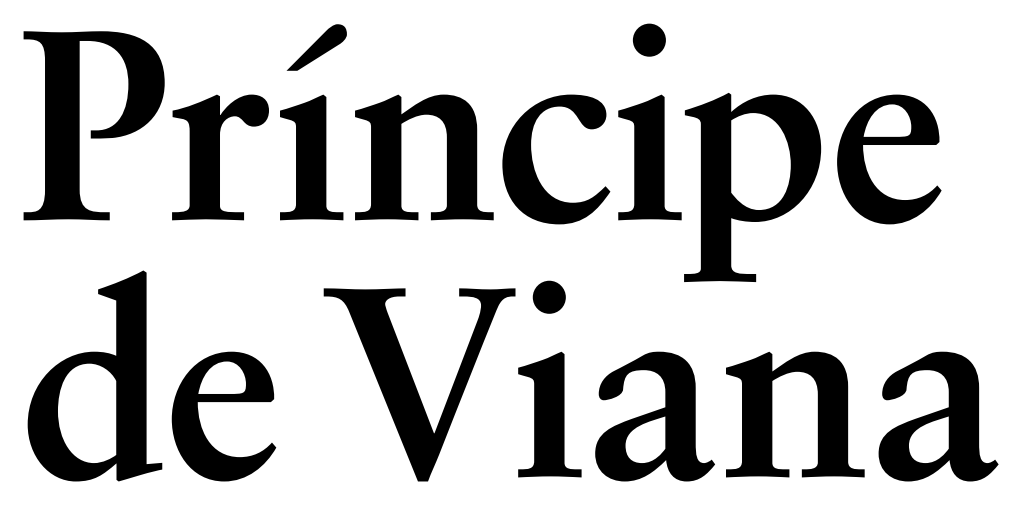

SEPARATA

Nafar egileen euskarazko liburuak 2019an

Ángel Erro Jiménez 


\section{Sumario / Aurkibidea}

\section{Príncipe de Viana}

Año LXXXI • n. ${ }^{\circ} 276$ • enero-abril de 2020

LXXXI. urtea $\cdot 276$. zk. 2020 ko urtarrila-apirila

\section{LITERATURA}

La realidad literaturizada y la ira contra la religión católica y el obispo de Pamplona en el «Libro segundo» de La familia de Errotacho, de Pío Baroja Miguel Ángel García de Juan

\section{HISTORIA}

La represión del protestantismo en el tribunal inquisitorial de Calahorra-Logroño (1550-1610)

Marcos Gómez García

Entre España y México, la libertad. El embajador Félix Gordón Ordás y su evocación de la figura del navarro Javier Mina en el marco de la guerra civil española

Un discurso inédito de Víctor Sainz de Robles en 1867

Emilio Cervantes Ruiz de la Torre

Política social y autogobierno en el núcleo de la conspiración carlista antirrepublicana

La botica del monasterio cisterciense de Santa María de La Oliva (Navarra) Juan Manuel Garde Garde

\section{DERECHO / ZUZENBIDEA}

Un debate sobre la Ley de 1841: Navascués, la Diputación, «El Mosquerino» y Ezquerra 


\section{Sumario / Aurkibidea}

\section{LOS TRABAJOS Y LOS DÍAS DEL AÑO 2019 / 2019ko LANAK ETA EGUNAK}

Tesis doctorales sobre temática navarra de ciencias humanas, sociales y jurídicas, leídas en 2019

(Según la Base de datos Teseo del Ministerio de Educación)

Medio siglo de Fontes Linguae Vasconum

Ekaitz Santazilia

Actividades en torno al cincuenta aniversario de la revista Cuadernos de

Etnología y Etnografía de Navarra

David Mariezkurrena

Autores y autoras navarras en castellano, año 2019

Mikel Zuza Viniegra

Nafar egileen euskarazko liburuak 2019an

Ángel Erro Jiménez

Viento a favor: talento y carácter. Navarra en la industria audiovisual (2019)

Marga Gutiérrez Díez

Tensión de rotura. Un panorama expositivo de 2019

Mireya Martín Larumbe

Hiriartea: crónica de un proyecto frustrado por una mala práctica en las políticas culturales

Arantza Santesteban

De escalas, tiempos y cultura: grado en Historia y Patrimonio por la UPNA

Fernando Mendiola Gonzalo, Miguel R. Wilhelmi

Investigación y difusión del patrimonio cultural navarro en la Universidad de

Navarra (2019)

Yolanda Cagigas Ocejo

Entrevista a Tomás Yerro Villanueva. Premio Príncipe de Viana de la Cultura 2019

Alicia Ezker Calvo

Si mi padre volviera, yo sería su escudero. Qué gran caballero era

Tomás Yerro. (Discurso)

Currículums

Analytic Summary

Normas para la presentación de originales / Idazlanak aurkezteko arauak /

Rules for the submission of originals

6 Príncipe de Viana (PV), 276, urtarrila-apirila, 2020 ISSN: 0032-8472 | ISSN-e: 2530-5824 | ISSN-L: 0032-8472 


\title{
Nafar egileen euskarazko liburuak 2019an
}

\author{
Ángel ERRO JimÉNEZ \\ Escritor/Idazlea \\ angerro@yahoo.es
}

DOI: https://doi.org/10.35462/pv.276.12

- Antoñana, Pablo, Odola oroi (Pamiela, 2019). Itzul.: Luis Mari Larrañaga. Narratiba itzulia

«Pablo Antoñana aitzindariaren Odola oroi honetan historia unitario bat erakusten da, mende erdiz bereizitako bi gerra zibiletako, 1874ko karlistaldiko eta 1936ko gerrako antzeko bi gertakari tartekatuz».

- Arretxe, Jon, Mesfidatu hitzez (Erein, 2019). Narratiba

«Abenturaren jarraipenak Parisa darama Toure [...] kamuflaturik afrikar jatorriko hainbeste jenderen artean. Lehendabiziko aldiz bere bizitzan Toure diruduna dela esan daiteke. [...] Bilatu gabe, berriz sartuko da peripezia arriskutsu batean, non bere erosotasuna eta bizitza bera ere airean jarriko duen. Argien Hiria Ilunbeltzena bihurtuko da gure detektibe igarlearentzat».

- Arrula Ruiz, Garazi, Idea Vilariño (Susa, 2019). Poesia itzulpena

«Pendulua bezala dabil Idea Vilariño (Montevideo, 1920-2009). Garazi Arrula Ruizek bere itzulpen bikainean ez dio kendu bat ere indarrik, ez dio kendu bat ere zaurgarritasunik. Uruguaiko 45eko belaunaldiko idazlea izan zen Onetti, Benedetti, Vitale, Falco... horiekin guztiekin batera». Igor Estankona, Deia, 2019/04/13.

- Astiz, Iñigo, Analfabetoa (Susa, 2019). Poesia

«Emango digu zer esanik Iñigo Astizek argitaratu berri duen poema liburuak. Bere laburrean, Analfabetoa hau mamitsua da, eta trinkoa, laberintikoa ia, erdi parteko pasarte batetik sartu eta berdin eramaten zaituena lehen olerki bakar soilera eta azken poemaren luze durduzagarrira. Tarteko guztiak ere bitan edo hirutan irakurtzekoak dira, hondo sakona baitaukate, azalean soilak eta zuzenak iruditu arren». Joannes Jauregi, Berria, 2019-06-09. 
- Astiz, Iñigo, Sandro Penna-Bilduma bat (Farmazia Beltza, 2019). Ilustratzailea: Pan Damaris. Poesia itzulpena

«Amodioaren poeta deitu izan zaio Sandro Penna italiarrari. Alabaina, bere poesian amodioa estuki lotuta ikus daiteke gaztetasunaren eta malenkoniaren edertasunarekin [...]. Itzulpen fina eta beharrezkoa proposatzen digu Astizek, idazle baten begiradatik gustuz osatua eta mimoz zaindua. Halakoa da baita ere argitaletxeak hartutako lana, edizioa, ilustrazioak eta hitzaurrea bikainak baitira». Irati Majuelo, Berria, 2020-03-15.

- Astiz, Iñigo, Joemak eta polasak (Elkar, 2019). Ilustratzailea: Maite Mutuberria. Poesia haur literatura

«Jolas egiteko poema-liburu ilustratua. Ume listoentzat edo heldu tontoentzako poema liburua da hau, [...] poemaz eta ilustrazioez osatua. Jostaria eta umoretsua ez ezik, iradokitzailea eta sortzailea. Ondo pasatu eta hitzen eta ilustrazioen indar iradokitzaileaz gozatzeko».

- Balda San Juan, Nerea, Atzerrian (Pamiela, 2019). Narratiba

«Nerea Balda idazleak argitaratutako lehen liburua da Atzerrian. Izenburuak dioen gisa, atzerrian kokatutako eleberri laburra ez ezik, atzerriari buruzko lan bat aurkezten digu. Itzultzaile gazte bat du protagonista, Euskal Herritik Londresera doana, bizi-helburutzat harturik erakunde prestigiotsu batean itzultzaile-lana lortzea. Atzerriratze horren atzean, ordea, etxetik aldentzeko beharra eta askatasunaren bilaketa igar daitezke». Irati Majuelo, Berria, 2019-10-27.

- Balentzia, Fermin (askoren artean), Vivir para cantarla / Kantuari emana (Txalaparta, 2019). Ez fikzioa

«Lagun talde batek erabaki du haren omenezko liburu-disko hau egitea, Ferminen bizitza, ondarea eta kantu ezagunenak bi diskotan biltzen dituena, eta horren aitzakian zenbait idazlek eta jende ezagunek testu bana idatzi diote».

- Chivite Ezkieta, Beatriz, Mugi/atu (Pamiela, 2019). Poesia

«Beatriz Chivite Ezkietak izugarrizko trebetasuna du baliabide erretoriko gutxirekin poesia egiteko, "Mugi/atu" bere azken poema liburuan frogatu daitekeenez. Bertan agertzen diren testuak biluzik agertzen dira, esentzialenera laburtura, gehiegizko lanketak poesia honen izaera baliogabetu ahal balu bezala». Javier Rojo, El Correo, 2019/09/28.

- Diaz De Ulzurrun Sagalá, Enrike, Iruñea (Elkar, 2019). Ilustratzailea: Asisko Urmeneta. Ez fikzioa

«Iruñea entzutean, berehala Sanferminak etortzen zaizkigu gogora. Baina Iruñeak beste gauza asko ere baditu jaiez gain, eta horietako batzuk biltzen ditu gida honek. Ibilbide bat proposatzen du kalez kale, plazaz plaza, txokoz txoko denetariko kontuak azalduta, [...] A1, A2, B1 eta B2 mailetara egokituta». 
- Diaz De Ultzurrun Sagalá, Itziar, Louis Aragon (Susa, 2019). Poesia itzulpena «Josteta dario Louis Aragonen poesia kaierari, Itziar Diez de Ultzurrun itzultzaile apartak ekarri digun honi; josteta, eta hitzen lilura, hala Aragonen irudi-kadentzia azkengabean nola Diez de Ultzurrunen itzulpen neurtuan». Joannes Jauregi, Berria, 2019/12/15.

- Erro, Angel, Lerro etena (2004-2018) (Elkar, 2019). Ez fikzioa

"Lerro etena dietarioko sarreretan bizitza bezainbeste literatura topa daiteke, bata bestearengandik bereiz balitezke, behintzat. Irakurlea berehala ohartuko denez, dietarioko testuak ez daude kronologikoki ordenatuta [...]. Erroren estiloa eta ahots narratiboa dira liburuaren ezaugarririk nabarmenenetakoak. Umorerik ez da falta dietarioa osatzen duten sarreretan, ez eta une gogorren kontakizunak ere». Peru Iparragirre, Berria, 2019/05/05

- Gartziandia, Alfontso, Itsu kolpeka (Alberdania, 2019). Narratiba

«Alfontso Gartziandia nafarraren lehen eleberria da "Itsu kolpeka". Urko Etxeberria du protagonista, ikertzaile izan nahiko lukeen gaztea. Ahalegin horretan dabil, baina enkargu berezi bat iristen zaionean okertuko zaio bidea». "Iruñeko kale aberatsetan eta aldiri ez hain dotoreetan, astebeteko tartean, Urkori egindako enkargu bereziak eragingo duen xake-partida tragiko bat».

- Gorostarzu Etxebeste, Ione, Ez da erditzea (Elkar, 2019). Poesia

"Amatasunaren gaian oinarrituta, Ione Gorostarzuk emakumearen paperaz hausnartzen du "Ez da erditzea" izenburuko poema liburu honetan. Ez dakit poesiaren alorrean paradigma aldaketa baten aurrean gauden, baina susmoa dut horixe gertatzen ari dela. [...] Hortik abiatuta, beste hainbat gai aipatzen dira: maitasuna, gorputza, sentimendu kontrajarriak, amarekiko erlazioak... honelako gaiak azaltzen dira bata bestearekin loturik, katebegiak bailiran». Javier Rojo, El Correo, 2019/05/11.

- Ibarra, Iñigo, Kenavo, zaku bete urre! (Pamiela, 2019). Haur literatura «Bertso zahar batzuen hariari tira eginez, gazte batzuk ezustekoz beteriko abentura dibertigarri batean murgilduko dira. Pirata baten altxorra izanen dute jo-muga. Toki arrotzetan ibiltzea tokatuko zaie, kultura berriak ezagutzea. Tartean, korapilorik latzena bezalaxe, haien arteko harremanak indartu eta sendotuko dira».

- Ijurko Irotz, Hodei, Basatza (Ataramiñe, 2019). Poesia «Espetxean 10 urte 6 hilabete eta 20 egun igaro nituen, horietako gehienak Galiziako espetxe batean pasa nituen, Pontevedrako probintzian, A Lama espetxean. Hortik liburu honen izena "BASATZA" [...]. Olerki liburu hau "egunkari olerkitu" batetatik ateratako poemekin idatzia dago».

- Jaka Garcia, Ana, Problemak biderkatzen (Elkar, 2019). Ilustratzailea: Iosu Mitxelena. Haur literatura

«Zazpi-zortzi urteko neska-mutilei zuzendutako bilduma da. Askatasunean eta aurreiritzirik gabeko haurtzaroaren aldarrikapena egingo dute neska alai, bihurri eta jakingura pareak. Noak eta Leak gogora ekarriko digute hazteak berarekin dakartzan pozak». 
- Jaka Garcia, Ana, Astindu gorputzak! (Elkar, 2019). Ilustratzailea: Iosu Mitxelena. Haur literatura

[Ikusi aurreko sarrera]

- Jimenez Maia, Josu, Aingurak eta arrangurak (Pamiela, 2019). Poesia "Josu Jimenez Maiak (Iruñea, 1967) hamarkada batean zehar idatzitako poemak bildu ditu Pamiela argitaletxearen eskutik plazaratu duen Aingurak eta arraingurak liburuan. [...] Poesia, orokorrean, baliabide ezinhobea bihurtzen du Maiak barne-barneko sentipenenen garraioirako. [...] Maiaren poesia, itzulinguruetan, hitzen bihurduran eta asoziazio paradoxikoetan (azken batean, hizkuntzan) du oinarria». Aitor Francos, Bilbao, 2019/03.

- Mindegia Petrirena, Miren, Maria Zugarramurdikoa eta sorginduak izan ziren emakumeak (Nabarralde, 2019)., Ilustratzailea: Adur Larrea. Komikia

«Mamu bat dabil Europan barrena. Sorginkeriaren mamua. Jaunaren 1609ko urtean, Pierre De Lancre inkisidoreak, d'Amou eta Urtubiako jaunek eskatuta, sorgin epaiketa eta erreketa oldeari hasiera eman zion Lapurdiko kostaldea».

- Munarriz, Juan Miguel, Euskararen genesiaz (Pamiela, 2019). Ez fikzioa «Lan honen helburua euskararen jatorria ikertzen saiatzea zen. [...] Hizkuntza-egoera desberdinak, garaiak eta beste hainbat berri jaso eta aztertu ahal izan ziren, hainbat non, jatorriaren bilaketak hizkuntzaren genesian barnatzera bideratu baitzuen ikerketa. [...] Emaitza hizkuntzaren garabideari buruzko hipotesia da, euskararen genesiarena, alegia».

- Ondarra Erdozia, Jesús, Bakaikuko leku-izenez hausnarrean (Pamiela, 2019). Ez fikzioa «Lan honen egilearen asmoa bere belaunaldira bizirik etorri diren toponimo guztiak biltzea izan da [...].

Artxiboak arakatuz, batik bat Nafarroako Artxibo Orokorreko dokumentuak XVI. mendetik hasita, lekuetan oinez ibiliz, lekuen geografia eta historia -izenen historia (aldaerak)- aztertuz, leku-izenen bilakabidea eta esanahia zehaztu nahi izan da».

- Perurena, Patziku, Bordarien sorrera eta bilakaera Leitzan eta Areson (1427-1925), (Pamiela, 2019). Ez fikzioa

«Gai honetaz egin den azterlanik zehatzena. [...] Leitzan bordarik zaharrena 1614 aldekoa da: Franki, Manuel Lasarte bertsolari haundia jaio zenekoa; eta 1726ko etxe erroldan 69 bordari ageri dira, nor bere bordan bizi dena familian; eta gezurra badirudi ere, lau ardiborda besterik ez. Holako beste mila datu zehatz, interes haundiko ikerlan honek jasotzen dizkizunak, 1427tik 1925era arte».

- Pla, Koldo, 80 pulsaciones / 80 taupada (Cénlit, 2019). Poesia

- Rubio Iturria, Miren, Txillardegi. Batasunaren pentsalaria (Txalaparta, 2019). Ez fikzioa

«XX. mendeko bigarren erdiko une erabakigarri guztietan Euskal Herriak behar izan duen pertsona izan da Txillardegi [...]. Pentsalari zein eragile, aitzindari izan baita 
hainbat arlotan [...]. Euskal Herriaren beraren historia ezagutuko du irakurleak Txillardegiren pausoei segika».

- Sanz, Daniel, Dena zekien gizona (autoeditatua). Narratiba «Hiri gorria, amodioa, bakardade latza. Burutu gabeko ametsak, Icaroren ilusio hutsalak. Sisiforen harria. Benetako adiskidetasuna, zoriontasunerako gogo urratua. Negar atsekabetua, bortizkeria. Hainbat bizitza, bizitza bakarrean».

- Suarez, Castillo, Irautera (Elkar, 2019). Poesia «Izan zitekeen maitasun poema-liburu bat. Izan zitekeen etsipenari eginiko oda bat. Izan zitekeen naturaren irudikapen erromantiko bat. [...] Finean, poema-liburu osoa eta ederra ondu du Castillo Suarezek, indar handiko irudi eta ideiak biltzen dituena hasieratik bukaeraraino». Irati Majuelo, Berria, 2019/10/13. 